J. Beerten, J. Verveckken, and J. Driesen, "Predictive Direct Torque Control for Flux and Torque Ripple Reduction," IEEE Transactions on Industrial Electronics, vol. 57, no. 1, pp. 404-412, Jan. 2010.

Digital Object Identifier: $\underline{\text { 10.1109/TIE.2009.2033487 }}$

URL:

http://ieeexplore.ieee.org/xpl/articleDetails.jsp?tp=\&arnumber=5280261

(C) 2009 IEEE. Personal use of this material is permitted. Permission from IEEE must be obtained for all other users, including reprinting/ republishing this material for advertising or promotional purposes, creating new collective works for resale or redistribution to servers or lists, or reuse of any copyrighted components of this work in other works. 


\title{
Predictive Direct Torque Control for Flux and Torque Ripple Reduction
}

\author{
Jef Beerten, Student Member, IEEE, Jan Verveckken, Student Member, IEEE, Johan Driesen Member, IEEE
}

\begin{abstract}
In this paper, a prediction scheme is presented to diminish both the torque and flux ripple in a Direct Torque Control (DTC) induction motor drive. In a discrete implementation of the classical DTC scheme, the time delay associated with data processing results in an additional torque and flux ripple. This part of the ripples can amount to a significant fraction of the overall ripple if the hysteresis bands are comparable to the maximum torque and flux variations in one sampling interval. This paper presents a prediction scheme with a low computational complexity and a low parameter sensitivity, both comparable to the standard DTC scheme. The prediction scheme can easily be extended to compensate for multiple time delays when the sampling frequency is raised but the computation time remains unchanged. Experimental results show the diminishing effect of the prediction scheme on the torque and flux ripples.
\end{abstract}

Index Terms-Direct Torque Control, Predictive Control, Induction Machine Torque Control, Discrete Time Systems

\section{NOMENCLATURE}

$B \quad$ Time interval for gate signals communication

$B_{\psi_{s}} \quad$ Width of stator flux hysteresis band

$B_{\text {in }} \quad$ Width of inner torque hysteresis band

$B_{\text {out }} \quad$ Width of outer torque hysteresis band

$b \quad$ Calculated values of $T_{e l}, \psi_{s}, \theta_{\psi_{s}}$

$C_{T} \quad$ Torque hysteresis controller output

$C_{\psi_{s}} \quad$ Stator flux hysteresis controller output

$C_{\theta} \quad$ Sectant of the stator flux vector

$d \quad$ Decisions $C_{\psi_{s}}, C_{T}, C_{\theta}$

$f_{s} \quad$ Sampling frequency

$i_{a b c} \quad$ Stator currents

$\vec{i}_{s}$

$M$

Stator current vector

Time interval for measurement communication

$\begin{array}{ll}m & \text { Measured values of } U_{d c}, i_{a b c} \\ R & \text { Time interval for data calculation }\end{array}$

$S_{a b c} \quad$ Inverter switching signals

$T_{e l} \quad$ Electromagnetic torque

$U_{d c} \quad$ Inverter DC bus voltage

$\vec{u}_{s} \quad$ Stator voltage vector

$\vec{\psi}_{s} \quad$ Stator flux vector

$\theta_{\psi_{s}} \quad$ Angular position of the stator flux vector

$x_{N} \quad$ Nominal value of variable $x$

Manuscript received February 27, 2009; Accepted for publication September 15, 2009.

Copyright (C) 2009 IEEE. Personal use of this material is permitted. However, permission to use this material for any other purposes must be obtained from the IEEE by sending a request to pubs-permissions @ ieee.org.

The authors are with the Department of Electrical Engineering (ESAT), Division ELECTA, Katholieke Universiteit Leuven, Kasteelpark Arenberg 10, bus 2445, 3001 Leuven-Heverlee, Belgium (e-mail: jef.beerten@esat.kuleuven.be).

\author{
$x[k] \quad$ Value of $x$ corresponding to time instant $t[k]$ \\ $\tilde{x} \quad$ Estimated value of $x$ \\ $\Delta_{k}^{k+1} x[k] \quad$ Incremental change $x[k] \rightarrow x[k+1]$
}

\section{INTRODUCTION}

INCE its introduction, Direct Torque Control (DTC) has $\checkmark$ become a powerful control scheme for the control of induction motor (IM) drives. The standard DTC scheme [1], [2] uses hysteresis comparators for the control of both stator flux magnitude and electromagnetic torque. This control structure ideally keeps both controlled parameters within the hysteresis bands and results in a non constant switching frequency. However, when the DTC scheme is used in a discrete implementation, both torque and flux exceed the bands imposed by the hysteresis comparators, due to the fixed sampling frequency. It is possible for the discrete scheme to operate as an analog one if the hysteresis bounds are chosen sufficiently large [3]. On the contrary, when the width of the bands is comparable to the maximum torque and flux variations during one sampling period, the excursions will be relatively large, partly due to the time delay that is caused by the data processing. Therefore, the sampling period is an important factor determining the control performance and switching frequency [4].

In the past, modified DTC based schemes have been presented in order to diminish the torque and flux ripple resulting from a discrete implementation. The incorporation of Space Vector Modulation (SVM) has shown to be an effective method to lower the ripples. SVM-based DTC schemes calculate an optimal reference voltage vector, that is thereafter applied to the machine using SVM [5]. The incorporation of Sliding Mode Control (SMC) into DTC-SVM has been presented in [6]-[9]. As an alternative to SVM, a multilevel inverter can also be used to increase the number of voltage vectors, as demonstrated by [10]. In [11], a variable application time of the voltage vectors during the sampling interval was presented, by considering the time necessary to reach the hysteresis bounds of the torque. However, the alternative schemes presented above operate in a rotating reference frame, which makes them computationally more intensive than the basic scheme.

Other schemes do not incorporate a transformation to a rotating reference frame, which is regarded as one of the key advantages of the basic DTC scheme. Romeral et al. [12] presented a variable duty cycle DTC scheme based on Fuzzy Logic to minimize the torque ripple. In [13], the torque ripple 


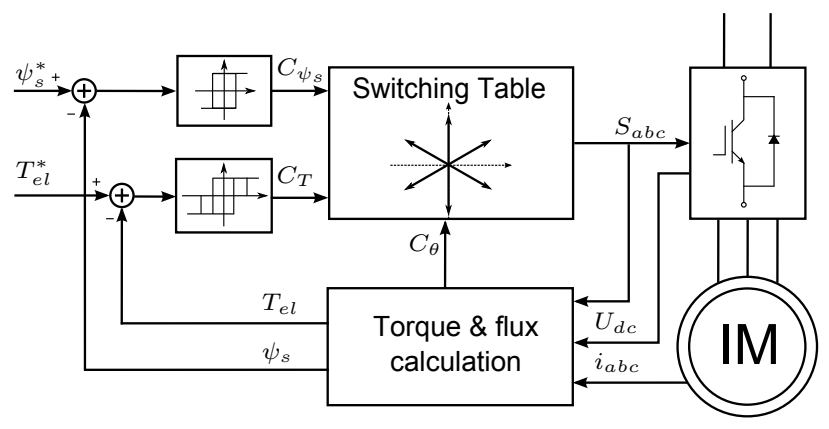

Fig. 1. Conventional DTC scheme with additive hysteresis torque comparator [23]

is reduced by replacing the three level hysteresis comparator by a more advanced torque controller. In order to reduce the torque and current ripples, Casadei et al. [14] presented a DTC scheme using Discrete SVM (DSVM) in combination with an extended switching table. More recently, Casadei et al. [15] presented a flux-weakening algorithm for DTC. Abad et al. [16] presented a predictive DTC strategy for a doubly fed induction machine in which the sampling period is divided in 3 variable time slots.

Recently, predictive DTC schemes are gaining increasing interests in the literature. Correa et al. [17] presented a onestep predictive torque control, using multilevel technology. A predictive DTC algorithm for Synchronous Reluctance Machines (SRM) was proposed in [18]. The scheme calculates the switching instants of two possible active voltage vectors to build the torque demand one step in advance. Recently, Miranda et al. [19] developed a predictive torque control strategy based on a discrete time state space machine model. The scheme explicitly takes into account the time delay due to the data processing by a two step prediction algorithm. In [20], [21] a model predictive DTC scheme is presented that predicts several future switch transitions, extrapolates the output trajectories and chooses the sequence of voltage vectors to keep flux and torque within their hysteresis bands while reducing the switching frequency.

In this paper, the prediction scheme presented in [22] is discussed in greater detail. This prediction algorithm can be easily implemented as an extension of the basic DTC scheme and compensates for the time delay due to the data processing. Contrary to the model based predictive schemes discussed above, this novel prediction algorithm does not need additional motor parameters. The scheme uses only previously calculated values of electromagnetic torque and flux. Furthermore, the prediction scheme can be extended to compensate for multiple delays when the data processing time cannot further be reduced. As discussed with the experimental results, this scheme offers significant possibilities to reduce both the torque and flux ripple.

\section{Discrete Direct Torque Control}

In this section, both the origin and the effect of the time delay resulting from a discrete implementation are discussed. Furthermore, the influence of the sampling moment and the numerical integration method for $\vec{\psi}_{s}$ are analyzed, which are

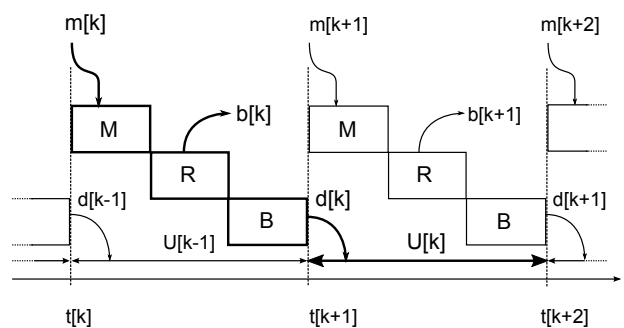

Fig. 2. Simplified data processing in a discrete implementation

the most important practical considerations for the prediction scheme presented in the next section to operate properly.

\section{A. Data processing time delay}

The basic DTC scheme is presented in Fig. 1. A three-level additive hysteresis torque comparator [23] is used in order to obtain a symmetric hysteresis band around the reference value.

When this scheme is implemented on a discrete time base, a finite time is needed to process the measured physical values and to calculate the appropriate voltage vector that has to be applied to the machine during the next sampling interval. This is depicted schematically in Fig. 2. The sampled stator currents $i_{a b c}$ and DC bus voltage $U_{d c}$ are available from measurements. In Fig. 2, the values of these sampled data at instants $t[k]$ are represented by $m[k]$. These measurements are sent to the processing unit during the time interval $M$. Using the corresponding gate signal series $S_{a b c}[k]$, the stator voltage vector $\vec{u}_{s}[k]$, stator current vector $\vec{i}_{s}[k]$, stator flux magnitude $\psi_{s}[k]$ and angle $\theta_{\psi_{s}}[k]$ and the electromagnetic torque $T_{e l}[k]$ are calculated. After comparing the values of $\psi_{s}[k]$ and $T_{e l}[k]$ to their reference values using hysteresis controllers, a voltage vector is selected from a switching table. Hereby, the sectant of the stator flux vector $\vec{\psi}_{s}[k]$ is taken into account via $\theta_{\psi_{s}}[k]$. These calculations are performed during the interval $R$ in Fig. 2 . The most important values, on which the voltage vector selection is based, are $T_{e l}[k], \psi_{s}[k]$ and $\theta_{\psi_{s}}[k]$, summarized as $b[k]$ in Fig. 2. The inputs to the switching table $\left(C_{\psi_{s}}[k], C_{T}[k]\right.$ and $C_{\theta}[k]$ from Fig. 1) are summarized as $d[k]$ in Fig. 2. These inputs determine the voltage vector $\vec{u}_{s}[k]$ that is applied during the next sampling interval $t[k+1] \rightarrow t[k+2]$. The interval $B$ (Fig. 2) is used to send the appropriate decisions to the inverter.

Therefore, when an excursion of either torque or flux from the hysteresis bands results from the measurements $m[k]$ at time instant $t[k]$, the accompanying decision only starts to have an effect at $t[k+1]$. As discussed in [22], this time delay can account for a significant fraction of the overall excursion of both torque $T_{e l}$ and stator flux $\psi_{s}$ outside the hysteresis bands. This is especially true when the maximum torque and flux change achieved by a voltage vector $\vec{u}_{s}$ that is applied during the entire sampling period $T_{s}$, is comparable to the width of the respective hysteresis bands.

\section{B. Influence of the sampling moment}

In the previous analysis, it was assumed that the data are sampled at the beginning of the sampling interval. It is clear from Fig. 2 that the overall torque and flux changing effects of 


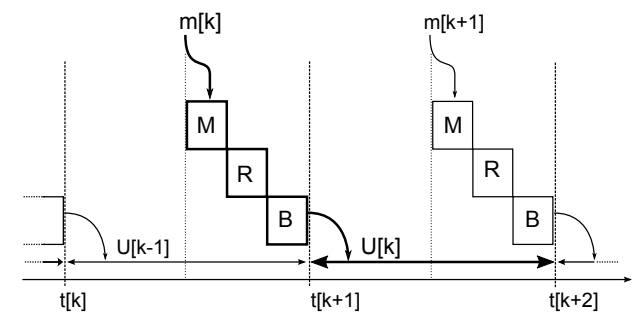

Fig. 3. Simplified data processing with measurements in the middle of the sampling interval

voltage vectors applied during the entire sampling period can be deduced directly from the measured data series $m[k]$. The change from $m[k] \rightarrow m[k+1]$, and therefore $b[k] \rightarrow b[k+1]$ is a result of voltage vector $\vec{u}_{s}[k-1]$ applied during $t[k] \rightarrow t[k+1]$, which again results from the measurements $m[k-1]$.

If the measurements are taken in the middle of the sampling interval, as depicted in Fig. 3, it is clear that this relation no longer holds. In this case, the effect of one voltage vector can no longer be deduced from the data series $b[k]$. For example, the change from $b[k]$ to $b[k+1]$ is partly caused by both $\vec{u}_{s}[k-1]$ and $\vec{u}_{s}[k]$.

In the prediction scheme presented in this paper, measurements take place at the beginning of the sampling interval, as discussed above. In the experimental setup, stator currents and DC bus voltage are measured directly after a short dead time, which has a negligible influence on the measurements.

\section{Numerical integration method}

Two commonly used time integration methods are the backward and forward Euler scheme. In this section, it will be shown that the forward Euler scheme most closely resembles the real stator flux evolution, which has to be calculated properly for the prediction scheme to operate correctly. A discrete approximation for the stator flux evolution is given by equations (1) - (2), respectively using the backward and forward Euler scheme. In these equations, the notation $x_{k}$ is the value of the variable $x$ at the time instant $t[k]$.

$$
\begin{aligned}
& \vec{\psi}_{s, k+1} \approx \vec{\psi}_{s, k}+\left(\vec{u}_{s, k+1}-R_{s} \vec{i}_{s, k+1}\right) \cdot T_{s} \\
& \vec{\psi}_{s, k+1} \approx \vec{\psi}_{s, k}+\left(\vec{u}_{s, k}-R_{s} \vec{i}_{s, k}\right) \cdot T_{s}
\end{aligned}
$$

For the stator flux and current vector $\vec{\psi}_{s, k}=\vec{\psi}_{s}[k]$ and $\vec{i}_{s, k}=$ $\vec{i}_{s}[k]$. On the contrary, the stator voltage vector applied during the interval $t[k] \rightarrow t[k+1]$ is based on the decisions $d[k-$ 1] from the previous sampling interval and therefore $\vec{u}_{s, k}=$ $\vec{u}_{s}[k-1]$. Equations (1) - (2) can thus be rewritten as (3) (4).

$$
\begin{aligned}
& \vec{\psi}_{s}[k+1] \approx \vec{\psi}_{s}[k]+\left(\vec{u}_{s}[k]-R_{s} \vec{i}_{s}[k+1]\right) \cdot T_{s} \\
& \vec{\psi}_{s}[k+1] \approx \vec{\psi}_{s}[k]+\left(\vec{u}_{s}[k-1]-R_{s} \vec{i}_{s}[k]\right) \cdot T_{s}
\end{aligned}
$$

The result from the forward Euler scheme most closely resembles the real value of the stator flux magnitude at the time instant $t[k+1]$. From Fig. 2, it is clear that the backward Euler scheme results in a stator flux that closely resembles the value at $t[k+2]$ instead of $t[k+1]$. The backward Euler scheme results in an erroneous torque value since $T_{e l}[k+1]$ will be calculated as the cross product of $\vec{i}_{s}[k+1]$ and a flux that closely resembles $\vec{\psi}_{s}[k+2]$. On the contrary, with the forward Euler scheme, $T_{e l}$ is calculated as the cross product of $\vec{i}_{s}$ and $\vec{\psi}_{s}$ at the same instant. In this way, the incremental changes in $\vec{i}_{s}$ and $\vec{\psi}_{s}$ are caused by the same voltage vector, which is necessary for the prediction scheme to operate properly.

\section{PREDICTION ALGORITHM}

In this section, a prediction scheme is presented to remove the part of the torque and flux ripple caused by the time delay described in the previous section. As discussed in [22], this part of the ripple can amount to a significant part of the overall ripple when the widths of the hysteresis bands are of the same order of magnitude as the maximum torque and flux variations during one sampling interval. An extension of this prediction scheme is presented as well, in order to double the sampling frequency when it is limited due to data-processing time restrictions. Finally, four dimensionless quantities are defined to evaluate the effectiveness of the prediction scheme in lowering both the torque and flux ripples.

\section{A. Basic principles}

The standard DTC scheme has a large robustness to parameter variations since only the stator resistance $R_{s}$ is needed to calculate $\vec{\psi}_{s}$ [24]. Alternative DTC schemes (recently [10], [11], [16], [19]) often incorporate inverse motor models to estimate the torque and flux variations, which makes these schemes less robust to motor parameter variations. The prediction scheme presented in this paper, on the contrary, only makes use of previously calculated values of $T_{e l}, \psi_{s}$ and $\theta_{\psi_{s}}$. These values are only sensitive to variations in $R_{s}$ via the time integration in (4). Furthermore, the predictive scheme does not use a transformation to a rotating $d q$-reference frame, which results in computational efforts comparable to the basic DTC scheme.

As described in the previous section, if the measurements are taken in the beginning of each sampling interval, the incremental changes in $T_{e l}, \psi_{s}$ and $\theta_{\psi_{s}}$ are the result of the voltage vector applied during the previous sampling interval. From Fig. 2, it is seen that a decision $d[k]$ based on a approximation $\tilde{b}[k+1]$ instead of $b[k]$, would compensate the additional torque and flux excursion caused by the time delay.

In order to classify the torque and flux changing effects of the different voltage vectors, a distinction is made between different types of voltage vectors. When DTC is implemented using a 2-level Voltage Source Inverter (VSI), 8 different voltage vectors, of which only 6 are classified as active voltage vectors, can be applied to the machine [25]. However, depending on the sectant of the stator flux $C_{\theta}$, different voltage vectors are used to control torque and flux. The distinction between the different voltage vectors put forward in this paper is therefore not based on the inverter switching states, but on the different hysteresis output values of $C_{T}$ and $C_{\psi_{s}}$. The 5 different types of voltage vectors resulting from this classification are depicted in Table I. 


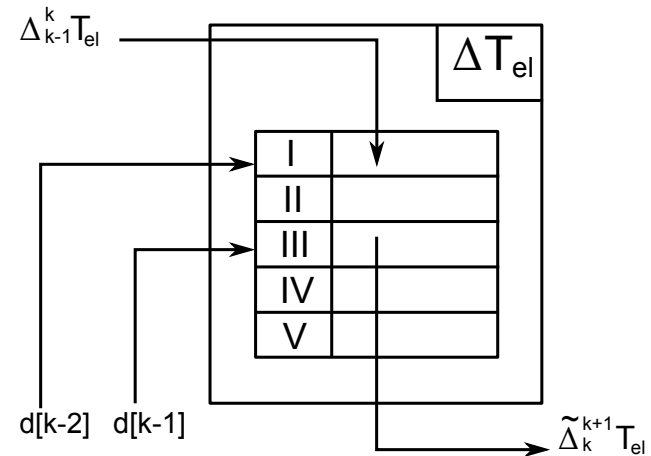

(a)

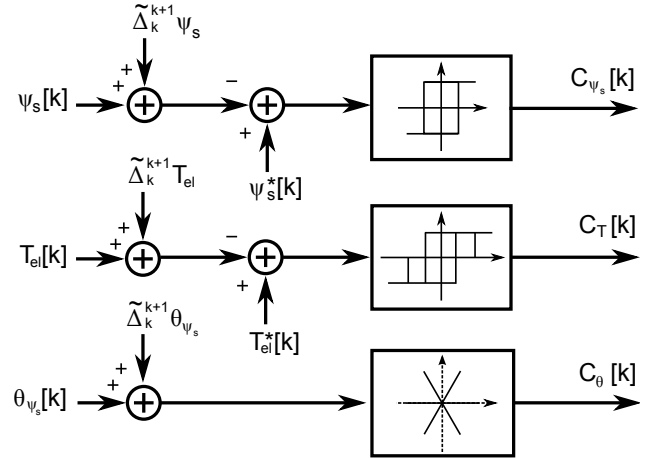

(b)

Fig. 4. Prediction algorithm: (a) Storage registers (e.g. for $\Delta T_{e l}$ ) (b) Alternative implementation of the hysteresis comparators

TABLE I

TYPES OF VOLTAGE VECTORS

\begin{tabular}{|c|c|c|c|}
\hline Type & \begin{tabular}{ll|} 
I & II \\
\end{tabular} & III & $\begin{array}{ll}\text { IV } & \text { V }\end{array}$ \\
\hline$C_{T}$ & +1 & 0 & -1 \\
\hline$C_{\psi_{s}}$ & +1 & -1 & -1 \\
\hline
\end{tabular}

TABLE II

EXCHANGE OF THE PREDICTIONS AT SECTANT CROSSINGS

\begin{tabular}{rrr||rrr|rrr}
\hline \multicolumn{1}{c||}{$\tilde{\Delta} T_{e l}, \tilde{\Delta} \theta_{\psi_{s}}$} & \multicolumn{8}{|c}{$\tilde{\Delta} \psi_{s}$} \\
\cline { 3 - 9 } \multicolumn{1}{c||}{} & \multicolumn{2}{c||}{$\omega_{\psi_{s}}>0$} & \multicolumn{3}{|c}{$\omega_{\psi_{s}}<0$} \\
\hline \hline$I$ & $\rightarrow$ & $I$ & $I$ & $\rightarrow$ & $I I$ & $-I$ & $\rightarrow$ & $I I$ \\
$I I$ & $\rightarrow$ & $I$ & $-I I$ & $\rightarrow$ & $I$ & $I I$ & $\rightarrow$ & $I$ \\
$I V$ & $\rightarrow$ & $V$ & $-I V$ & $\rightarrow$ & $V$ & $I V$ & $\rightarrow$ & $V$ \\
$V$ & $\rightarrow$ & $I V$ & $V$ & $\rightarrow$ & $I V$ & $-V$ & $\rightarrow$ & $I V$ \\
\hline
\end{tabular}

From Fig. 2 it is clear that an estimation $\tilde{b}[k+1]$ is needed to seemingly base the decision $d[k]$ on $b[k+1]$ instead of $b[k]$. In the proposed prediction algorithm, the unknown change from $b[k] \rightarrow b[k+1]$ can be estimated using the decision $d[k-1]$ by which it is caused. Since $b[k]$ is known from the measured data $m[k]$, the estimation $\tilde{b}[k+1]$ can be rewritten as $b[k]+$ $\tilde{\Delta}_{k}^{k+1} b[k]$.

The prediction algorithm put forward in this paper uses 5 registers to store the incremental changes in torque $\Delta T_{e l}$, stator flux magnitude $\Delta \psi_{s}$ and stator flux angle $\Delta \theta_{\psi_{s}}$ by the 5 types of voltage vectors.

Fig. 4 shows how these incremental changes of $T_{e l}$ are stored temporarily and serve as a prediction $\tilde{\Delta}_{k}^{k+1} b[k]$ to base the decisions $d[k]$ on $\tilde{b}[k+1]$ instead of $b[k]$. The hysteresis outputs $d[k-1]$ determine the type of voltage vector applied during the time interval $t[k] \rightarrow t[k+1]$. The incremental changes that are stored in the corresponding memories serve as predictions $\tilde{\Delta}_{k}^{k+1} b[k]$, which are added to the calculated values of $\psi_{s}[k], T_{e l}[k]$ and $\theta_{\psi_{s}}[k]$ as shown in Fig. 4b. Meanwhile, the now available incremental changes $\Delta_{k-1}^{k} b[k]$ are stored in the memory corresponding to the type of voltage vector that has caused this incremental change, as shown in Fig. 4a.

At system start-up, the predictions are reset to zero. Therefore, as long as a certain type of voltage vector has not yet been applied, the corresponding prediction is equal to zero. When the voltage vector is used for the first time, the control

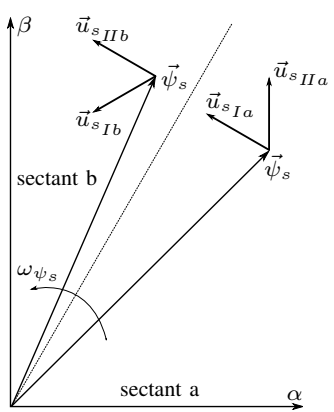

(a)

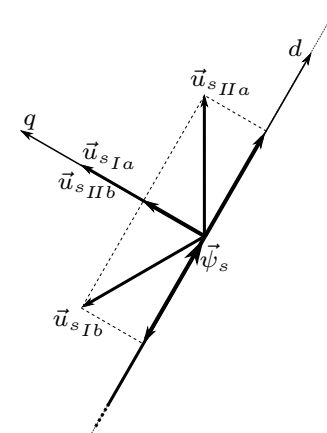

(b)
Fig. 5. (a) Change of applied voltage vector at a sectant crossing of the stator flux linkage (b) $d q$-components in a statorflux fixed reference frame

scheme momentarily acts as the conventional DTC scheme for one sampling period.

\section{B. Sectant crossings}

When the stator flux $\vec{\psi}_{s}$ crosses a sectant boundary, the incremental changes that are stored in the memories do no longer provide an accurate representation of the flux and torque changing effects of their corresponding types of voltage vector. This is due to the fact that the voltage vectors applied to the machine change when the stator flux sectant changes, as dictated by the switching table. In order to provide an accurate prediction after a sextant change, the registers for the different voltage vectors are exchanged, corresponding to the flux- and torque producing capabilities of the different voltage vectors at the sectant crossing.

Fig. 5a graphically depicts the change of the torque increasing voltage vectors (type $I$ and $I I$ ) when $\vec{\psi}_{s}$ moves from one sectant to another. Fig. 5b depicts the $d$ - and $q$-components of the applied voltage vectors in a stator flux linkage fixed reference frame at a sectant crossing. In [26], it is shown that the $d$-component is responsible for the change of the stator flux magnitude $\psi_{s}$ whereas the $q$-component is responsible for the stator flux angular speed and therefore the change in both stator flux angle $\theta_{\psi_{s}}$ and the torque $T_{e l}$.

Analyzing the components of the different types of voltage vectors in the $d q$-reference frame at the sectant crossing (Fig. $5 b)$ results in the exchanges presented in Table II. For the exchanges related to the stator flux magnitude, the rotational 


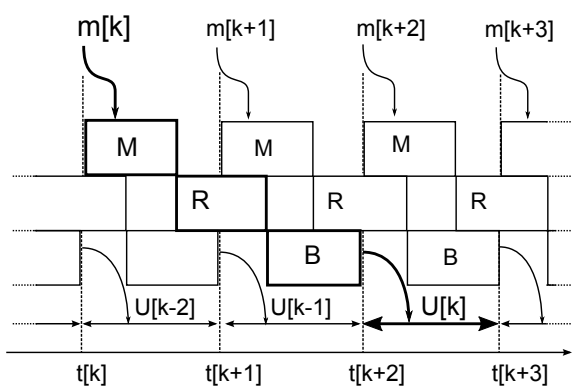

Fig. 6. Simplified data processing with additional time delay

direction of the stator flux vector $\vec{\psi}_{s}$ (i.e. $\omega_{\psi_{s}}$ ) has to be taken into account, since the $d$-axis projections are equal in magnitude but opposite in sign, as shown in Fig. 5b.

\section{Additional time delay}

In the experimental setup, which is discussed further on, the sampling frequency was limited due to the time needed for the data processing. The prediction scheme was extended in order to introduce an additional time delay, as shown in Fig. 6. This offers the possibility to double the sampling frequency, while maintaining the same overall data processing time.

As a second step the prediction scheme was extended to compensate for this additional time delay, by basing the decision $d[k]$ on estimations $\tilde{T}_{e l}[k+2], \tilde{\psi}_{s}[k+2]$ and $\tilde{\theta}_{\psi_{s}}[k+2]$. The real and yet unknown values $b[k+2]$ are now approximately written as $\tilde{b}[k+2]=b[k]+\tilde{\Delta}_{k}^{k+1} b[k]+\tilde{\Delta}_{k+1}^{k+2} b[k]$.

This extended prediction scheme, intended to provide a compensation for multiple time delays without additional computational efforts, is used to further increase both sampling and switching frequency, hence resulting in lower torque, flux and current ripples.

\section{Ripple reduction evaluation}

To address the effect of the prediction scheme on the torque and flux ripples in a general way, four dimensionless quantities are introduced in this part.

The Hysteresis Excursion Coefficient $H E C_{x}$, as defined in (5), describes the ability to maintain the controlled quantity $x$, which can be either $T_{e l}$ or $\psi_{s}$, within the hysteresis bands. It is defined as the average fraction of the overall ripple outside the hysteresis bands (with $2 B_{x}$ the width of the hysteresis band).

$$
H E C_{x}=\int_{t_{1}}^{t_{2}} \frac{\max 0,\left|x-x^{*}\right|-B_{x}}{\left|x-x^{*}\right|} \mathrm{d} t
$$

It therefore compares the control behavior of the discrete scheme to that of an analog implementation, in which the control scheme can maintain the torque and stator flux inside the hysteresis bands, with the exception of a stator flux breakdown when a zero voltage vector is applied. This quantity determines to what extent the prediction scheme improves the hysteresis control.

The Deviation from Reference Factor $\left(D R F_{x}\right)$, as defined in (6), takes into account the deviation of $x$ from the reference value $x^{*}$, by normalizing the average deviation to the nominal

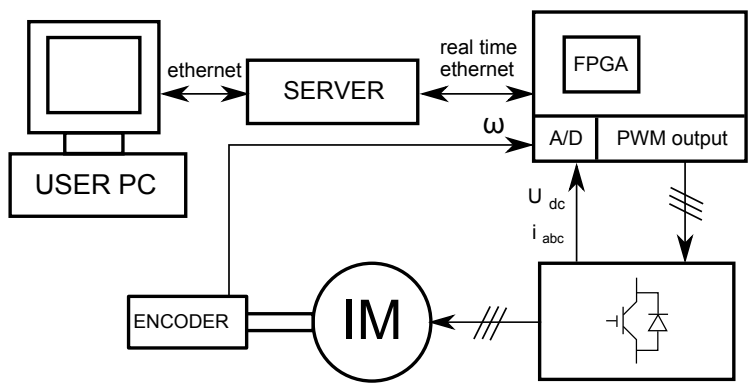

Fig. 7. Experimental setup

value $x_{N}$. This quantity is a measure to determine the overall ripple reduction.

$$
D R F_{x}=\int_{t_{1}}^{t_{2}} \frac{\left|x-x^{*}\right|}{x_{N}} \mathrm{~d} t
$$

When the hysteresis bands are chosen relatively large, a smaller fraction of the overall ripple is located outside the hysteresis band, resulting in a low value of $H E C_{x}$. This is accounted for by both $D R F_{x}$ and the Sampling Frequency Coefficient $\left(S F C_{x}\right)$, which is defined as the sampling frequency $f_{s}$ to the maximum switching frequency in an analog implementation, as shown in (7). This maximum switching frequency can be approximately calculated as the inverse of the time necessary to cross the entire hysteresis band $2 B_{x}$ when the derivative of $x$ is at maximum.

$$
S F C_{x}=\frac{f_{s}}{\left.\frac{\mathrm{d} x}{\mathrm{~d} t}\right|_{\max } /\left(2 \cdot B_{x}\right)}
$$

This coefficient $S F C_{x}$ is a measure for the exploitation of the control abilities available in the discrete implementation. A value of $S F C>1$ indicates that the hysteresis bands are chosen larger than the maximum variation of $x$ in one sampling period $T_{s}$, whereas a small value $S F C<1$ indicates that, in the worst case, the entire hysteresis band can be crossed in one sampling period. With increasing hysteresis bands, this quantity will increase accordingly to indicate that more stringent reductions could be used for the hysteresis bands. It must be stressed upon that the real torque variation during one sampling interval is not constant and it depends on both the operation condition and the position of $\vec{\psi}_{s}$ when the voltage vector is applied as shown in [26]. Therefore, using the maximum derivative can be considered as a 'worst case'.

Finally, the quantities from (5)-(7) are multiplied to obtain the Total Excursion Coefficient $\left(T E C_{x}\right)$, shown in (8).

$$
T E C_{x}=H E C_{x} \times D R F_{x} \times S F C_{x}
$$

These quantities will be used in the next section to analyze the effectiveness of the control scheme at reducing the ripples.

\section{EXPERIMENTAL RESULTS}

A schematic of the experimental setup is depicted in Fig. 7, in which the induction motor (IM) is fed by a 2-level Voltage Source Inverter (VSI). The motor parameters are given in Table III. The torque reference for the DTC loop is generated by a speed control loop, with the motor speed obtained by 
TABLE III

EXPERIMENTAL SETUP PARAMETERS

\begin{tabular}{lcr}
\hline Parameter & Symbol & Value \\
\hline Number of pole pairs & $p$ & 1 \\
Nominal power $(\mathrm{kW})$ & $P_{N}$ & 4 \\
Nominal speed $(\mathrm{RPM})$ & $n_{N}$ & 2850 \\
Nominal frequency $(\mathrm{Hz})$ & $f_{N}$ & 50 \\
Nominal torque $(\mathrm{Nm})$ & $T_{e l}$ & 13.4 \\
Line Voltage $(\mathrm{V})$ & $U_{N}$ & 230 \\
Stator inductance $(\mathrm{mH})$ & $L_{s}$ & 102 \\
Rotor inductance $(\mathrm{mH})$ & $L_{r}$ & 103 \\
Stator resistance $(m \Omega)$ & $R_{s}$ & 451 \\
Rotor resistance $(m \Omega)$ & $R_{r}$ & 532 \\
Iron loss shunt resistance $(\Omega)$ & $R_{F e}$ & 217 \\
Mechanical inertia $\left(\mathrm{kgm}^{2}\right)$ & $J$ & 0.0131 \\
Stator flux linkage reference $(\mathrm{Wb})$ & $\psi_{s}^{*}$ & 0.5 \\
\hline
\end{tabular}

TABLE IV

EXPERIMENTAL CONFIGURATIONS

\begin{tabular}{l|c|cccc}
\hline Case & Type & $\begin{array}{c}f_{s} \\
(k H z)\end{array}$ & $\begin{array}{c}B_{\text {in }} \\
(\mathrm{Nm})\end{array}$ & $\begin{array}{c}B_{\text {out }} \\
(\mathrm{Nm})\end{array}$ & $\begin{array}{c}B_{\psi_{s}} \\
(\mathrm{mWb})\end{array}$ \\
\hline $\mathrm{A}$ & Conventional DTC & 10 & 0.75 & 7 & 2.50 \\
$\mathrm{~B}$ & Predictive DTC & 10 & 0.75 & 7 & 2.50 \\
$\mathrm{C}$ & Ext. predictive DTC & 20 & 0.75 & 7 & 2.50 \\
$\mathrm{D}$ & Ext. predictive DTC & 20 & 0.30 & 3 & 1.25 \\
\hline
\end{tabular}

measurement with a 1024 pulse incremental rotary encoder. The VSI is part of the Triphase rapid-prototyping platform [27] whose latest experimental prototype is described in [28]. The platform uses the power electronic hardware of a commercial KEB 16.F5.C16-360A inverter of which the original control circuits are replaced by an Altera Cyclone II EP2C Field Programmable Gate Array (FPGA). The FPGA handles dead time generation, stator currents, dc bus voltage and encoder measurements. The FPGA communicates the measured values in real-time to a Xenomai extended Linux based server, from which it also receives the reference output voltages for the next control cycle. The server is connected to a user PC from which a control program, constructed in Matlab/Simulink, is compiled to the server. This user PC also communicates to the Linux based server to exchange measurements and control variables.

The sampling frequencies and the width of the hysteresis bands for stator flux linkage and torque for the different experimental configurations are given in Table IV. The width of the hysteresis bands is in the order of magnitude of the maximum torque and flux variations during one sampling interval. Fig. 8 shows a detailed picture of torque and stator flux for a constant torque and flux reference in a conventional DTC scheme. A relatively large fraction of the overall ripple is caused by the data-processing time delay. Fig. 9 shows the diminishing effect of the predictive DTC scheme on both torque and flux ripples.

In the experimental setup, the sampling frequency is limited to $10 \mathrm{kHz}$ due to data-processing time restrictions. As discussed above, the prediction scheme can be extended in order to provide a compensation for the additional time delay that

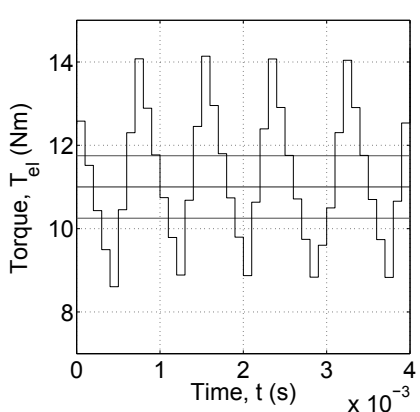

(a)

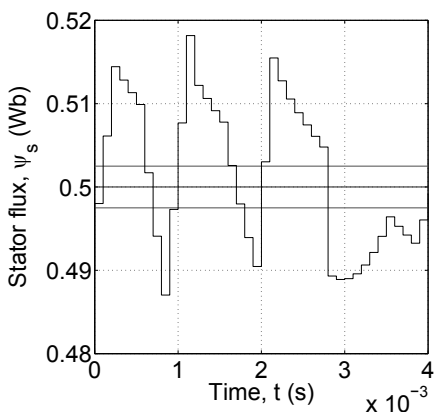

(b)
Fig. 8. Conventional DTC: Torque (a) and flux (b). Configuration: Case A, $\omega=100 \mathrm{rad} / \mathrm{s}, T_{\text {load }}=11 \mathrm{Nm}$

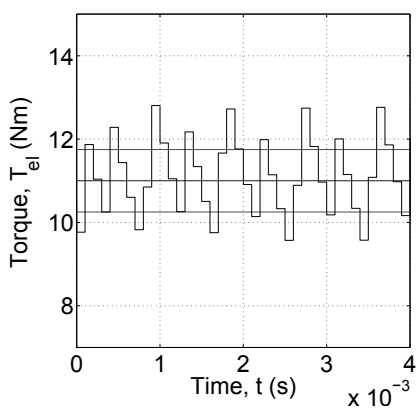

(a)

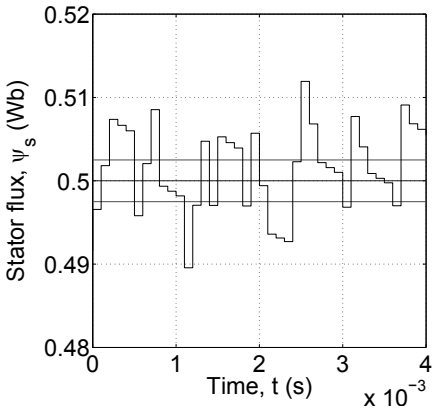

(b)
Fig. 9. Predictive DTC: Torque (a) and flux (b). Configuration: Case B, $\omega=100 \mathrm{rad} / \mathrm{s}, T_{\text {load }}=11 \mathrm{Nm}$

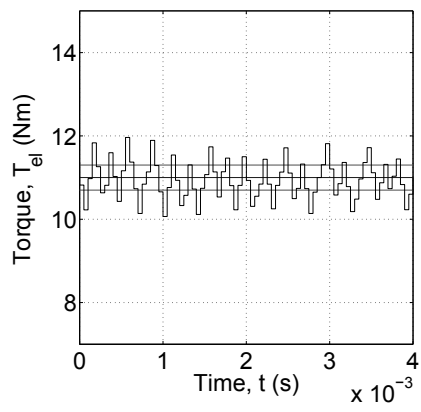

(a)

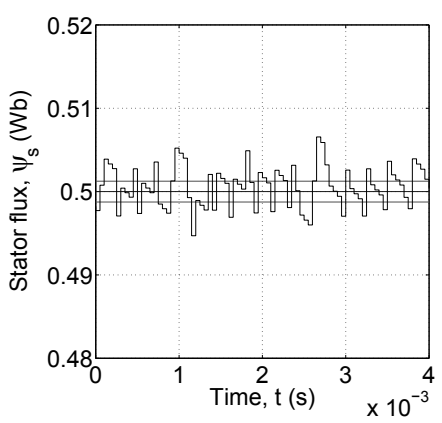

(b)
Fig. 10. Extended predictive DTC: Torque (a) and flux (b). Configuration: Case D, $\omega=100 \mathrm{rad} / \mathrm{s}, T_{\text {load }}=11 \mathrm{Nm}$

is introduced in order to leave the calculation time unaltered when the sampling frequency is raised to $20 \mathrm{kHz}$. Since the sampling period is diminished, the maximum torque and flux variations during one sampling period become smaller as well. Therefore the hysteresis bands are chosen smaller (case D) in order to exploit the additional control options. The extended predictive DTC scheme results in an additional reduction of both the torque and flux ripple, as shown in Fig. 10. The values of rms torque ripples are given in Fig. 11 for different values of motor speed and motor loads. As observed from Fig. 11, the predictive DTC scheme (case B) improves the steadystate torque ripple performance. The extended predictive DTC scheme (case C) reduces the torque ripple further. An even further reduction is possible by decreasing the hysteresis bands accordingly (case D).

Fig. 12 shows the incremental changes in torque and stator 


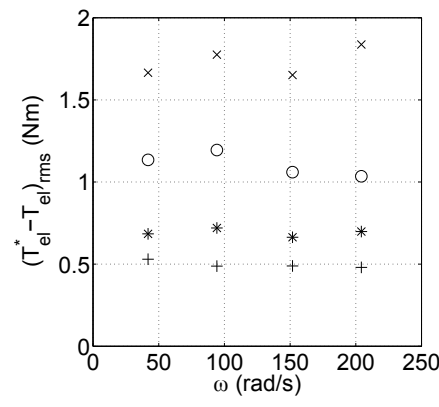

(a)

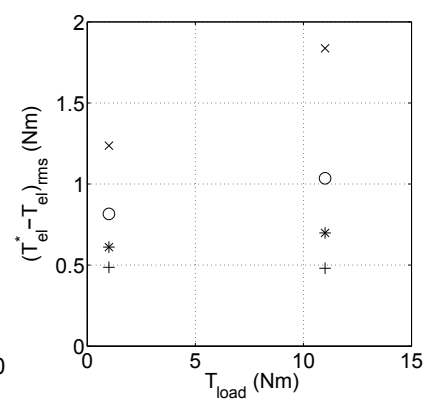

(b)
Fig. 11. Rms value of the torque ripple (a) versus motor speed $\omega$ at $T_{\text {load }}=11 \mathrm{Nm},(\mathrm{b})$ versus $T_{\text {load }}$ at $\omega=200 \mathrm{rad} / \mathrm{s}$

Legend: x: Conventional DTC (case A), o: Predictive DTC (case B). $*$ : Extended predictive DTC (case C), +: Extended predictive DTC with decreased hysteresis bands (case D)

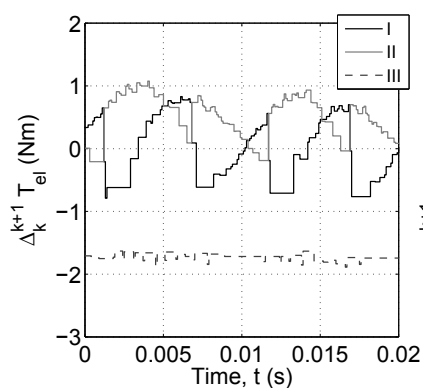

(a)

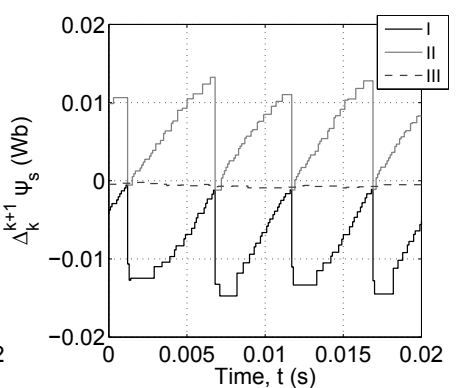

(b)
Fig. 12. Torque predictions (a) and flux predictions (b). Configuration: Case B, $\omega=200 \mathrm{rad} / \mathrm{s}$ and $T_{\text {load }}=11 \mathrm{Nm}$

flux magnitude that are stored and serve as predictions in the predictive DTC scheme for voltage vectors $I \rightarrow I I I$. These incremental changes, that result from the calculated values of torque and flux, closely resemble the theoretical values derived in [11] where an induction motor model is used for the predictions. However, the predictive DTC scheme presented in this paper does not need such a model since the predictions are based on previously calculated values of torque and flux changes. When the working conditions vary, the changes are reflected in the measured values of torque and flux, and are therefore automatically and instantaneously adopted by the prediction scheme, resulting in a decreased torque and flux ripple at different operation speeds and loads. The abrupt variations of the incremental torque and flux changes that can be observed in Fig. 12 result from sectant crossings. This justifies the exchange of the storage registers at sectant crossings, as proposed in section III-B.

Fig. 13 shows the beneficial effects of the predictive scheme on the stator currents. The predictive DTC scheme (Fig. 13b) significantly reduces the ripple that exists in a conventional DTC scheme (Fig. 13a). The extended predictive scheme with an additional time delay and a higher sampling frequency (Fig. 13c) further improves the stator current ripple.

In order to numerically verify the effect of the prediction scheme on the ripples, the dimensionless quantities defined in the previous section are calculated for the experiments of which extracts are shown in Figs. 8 - 10. Additionally, an experiment was carried out at $20 \mathrm{kHz}$, but with the same

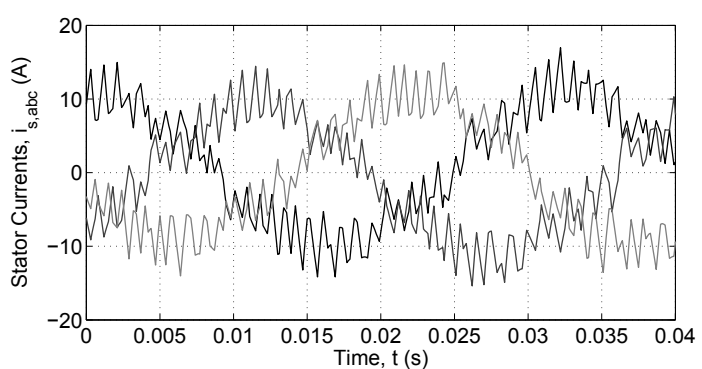

(a)

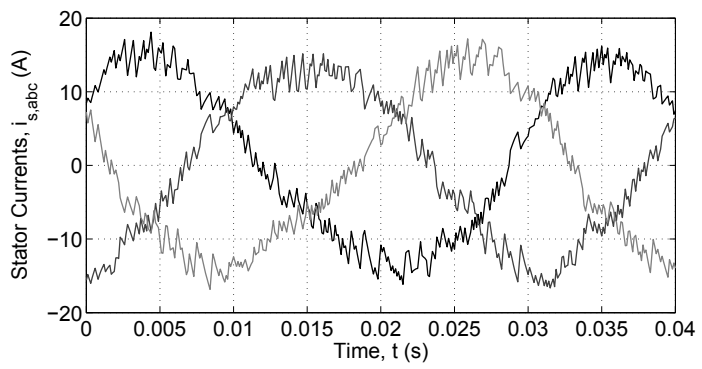

(b)

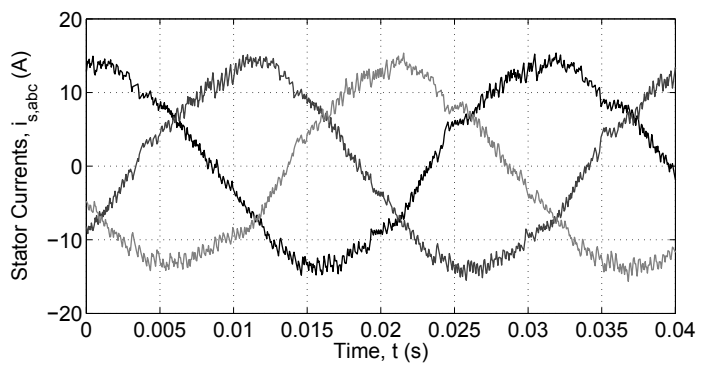

(c)

Fig. 13. Stator currents: (a) Conventional DTC (case A), (b) Predictive DTC (case B) and (c) extended predictive DTC (case D). $\omega=200 \mathrm{rad} / \mathrm{s}$ and $T_{\text {load }}=11 \mathrm{Nm}$

hysteresis bands as with the $10 \mathrm{kHz}$ experimental setup (case $C$ ). The maximum torque and stator flux magnitude derivatives are obtained from the calculated values and are equal to $26.15 \mathrm{Nm} / \mathrm{ms}$ and $0.175 \mathrm{~Wb} / \mathrm{ms}$ respectively. The experiments are carried out using constant torque and flux references $T_{e l}^{*}$ as discussed above, during a time frame of $200 \mathrm{~ms}$. Tables V and VI summarize the results.

Comparing $H E C$ and $D R F$ for cases $A$ and $B$, it can be concluded that the prediction scheme greatly diminishes both torque and flux ripples, which was already visible in Figs. 8 - 10. Comparing $H E C_{T}$ and $H E C_{\psi_{s}}$ for both cases $A$ and $B$, it is seen that the hysteresis bands for the flux are more stringent than those of the torque, resulting in a larger fraction outside the hysteresis bands. However, this is accounted for by $S F C$, where $S F C_{\psi_{s}}<S F C_{T}$. A part of the higher value of $H E C_{\psi_{s}}$, compared to $H E C_{T}$, is due to the fact that the zero voltage vectors cause a stator flux breakdown at sectant crossings, which can force $\psi_{s}$ outside the hysteresis bands, even when a flux increase is commanded. When the sampling frequency is increased but the hysteresis bands are left unaltered (cases $B$ and $C$ ), the portion of the ripple outside the hysteresis bands diminishes $(H E C)$ as well as the overall ripple $(D R F)$. However, the accompanying increase of $S F C$ indicates lower computational efficiency. The increase 
TABLE V

DIMENSIONLESS TORQUE RIPPLE EVALUATION QUANTITIES

\begin{tabular}{l|ccc|c}
\hline Case & $H E C_{T}$ & $D R F_{T}$ & $S F C_{T}$ & $T E C_{T}$ \\
\hline $\mathrm{A}$ & 0.558 & 0.113 & 0.574 & 0.036 \\
$\mathrm{~B}$ & 0.346 & 0.067 & 0.574 & 0.013 \\
$\mathrm{C}$ & 0.188 & 0.048 & 1.147 & 0.010 \\
$\mathrm{D}$ & 0.411 & 0.031 & 0.459 & 0.006 \\
\hline
\end{tabular}

TABLE VI

DIMENSIONLESS STATOR FLUX RIPPLE EVALUATION QUANTITIES

\begin{tabular}{l|ccc|c}
\hline Case & $H E C_{\psi_{s}}$ & $D R F_{\psi_{s}}$ & $S F C_{\psi_{s}}$ & $T E C_{\psi_{s}}$ \\
\hline $\mathrm{A}$ & 0.764 & 0.017 & 0.286 & 0.0036 \\
$\mathrm{~B}$ & 0.596 & 0.009 & 0.286 & 0.0015 \\
$\mathrm{C}$ & 0.552 & 0.008 & 0.571 & 0.0024 \\
$\mathrm{D}$ & 0.705 & 0.006 & 0.286 & 0.0012 \\
\hline
\end{tabular}

of $T E C_{\psi_{s}}$ indicates that the relatively small decrease of flux ripple does not justify doubling the switching frequency while leaving the flux hysteresis bands unaltered. Diminishing the hysteresis bands (case $D$ ) results in smaller ripples $(D R F)$, but with a larger fraction outside of the hysteresis bands $(H E C)$.

\section{CONCLUSiON}

The novel prediction scheme presented in this paper uses only previously calculated values of torque and flux, which results in a low computational complexity, comparable to the conventional DTC scheme. The prediction scheme uses incremental changes in stator flux magnitude, stator flux angle and electromagnetic torque, which are stored in memories and used as a prediction in order to compensate for the time delay caused by the data processing. The scheme can be easily extended to raise the sampling frequency, while maintaining the same computation time. This extended prediction scheme including multiple predictions further diminishes the ripples when the data processing time forms a restrictive parameter. The experimental results here presented show the effectiveness of the novel prediction scheme in diminishing both torque and flux ripples at different loads and speeds. The dimensionless quantities introduced in this paper take into account the effect of the width of hysteresis bands and the limitations due to the fixed sampling frequency. This offers the possibility to quantify the ripple reduction of the prediction scheme. The values of these quantities demonstrate the significant reduction of both torque and flux ripple resulting from the prediction scheme. Furthermore, it is shown that an extension of the prediction scheme to increase the sampling frequency is only meaningful when the hysteresis bands are reduced appropriately.

\section{ACKNOWLEDGMENT}

Jan Verveckken is funded by a research grant from the "Institute for the Promotion of Innovation through Science and Technology in Flanders (IWT-Vlaanderen)".

\section{REFERENCES}

[1] I. Takahashi and T. Noguchi, "A new quick-response and high-efficiency control strategy of an induction motor," IEEE Trans. Ind. Appl., vol. IA22, no. 5, pp. 820-827, Sep. 1986.

[2] M. Depenbrock, "Direct self-control (DSC) of inverter-fed induction machine," IEEE Trans. Power Electron., vol. 3, no. 4, pp. 420-429, Oct. 1988.

[3] G. S. Buja and M. P. Kazmierkowski, "Direct torque control of PWM inverter-fed ac motors - a survey," IEEE Trans. Ind. Electron., vol. 51, no. 4, pp. 744-757, Aug. 2004.

[4] J. Kang and S. Sul, "Analysis and prediction of inverter switching frequency in direct torque control of induction machine based on hysteresis bands and machine parameters," IEEE Trans. Ind. Electron., vol. 48, no. 3, pp. 545-553, Jun. 2001.

[5] K. B. Lee, F. Blaabjerg, and T. W. Yoon, "Speed-sensorless DTC-SVM for matrix converter drives with simple nonlinearity compensation," IEEE Trans. Ind. Appl., no. 6, pp. 1639-1649, Nov./Dec. 2007.

[6] C. Lascu, I. Boldea, and F. Blaabjerg, "Variable-structure direct torque control - a class of fast and robust controllers for induction machine drives," IEEE Trans. Ind. Electron., no. 4, pp. 785-792, Aug. 2004.

[7] - "Direct torque control of sensorless induction motor drives: a sliding-mode approach," IEEE Trans. Ind. Appl., vol. 40, no. 2, pp. 582-590, Mar./Apr. 2004.

[8] C. Lascu and A. M. Trzynadlowski, "Combining the principles of sliding mode, direct torque control, and space-vector modulation in a highperformance sensorless ac drive," IEEE Trans. Ind. Appl., no. 1, pp. 170-177, Jan./Feb. 2004.

[9] C. Lascu, I. Boldea, and F. Blaabjerg, "Very-low-speed variable-structure control of sensorless induction machine drives without signal injection," IEEE Trans. Ind. Electron., vol. 41, no. 2, pp. 591-598, Mar./Apr. 2005.

[10] S. Kouro, R. Bernal, H. Miranda, C. A. Silva, and J. Rodriguez, "Highperformance torque and flux control for multilevel inverter fed induction motors," IEEE Trans. Power Electron., vol. 22, no. 6, pp. 2116-2123, Nov. 2007.

[11] V. Ambrožič, G. S. Buja, and R. Menis, "Band-constrained technique for direct torque control of induction motor," IEEE Trans. Ind. Electron., no. 4, pp. 776-784, Aug. 2004.

[12] L. Romeral, A. Arias, E. Aldabas, and M. Jayne, "Novel direct torque control (DTC) scheme with fuzzy adaptive torque-ripple reduction," IEEE Trans. Ind. Electron., vol. 50, no. 3, pp. 487-492, Jun. 2003.

[13] N. R. N. Idris and A. H. M. Yatim, "Direct torque control of induction machines with constant switching frequency and reduced torque ripple," IEEE Trans. Ind. Electron., vol. 51, no. 4, pp. 758-767, Aug. 2004.

[14] D. Casadei, F. Profumo, G. Serra, and A. Tani, "FOC and DTC: two viable schemes for induction motors torque control," IEEE Trans. Power Electron., vol. 17, no. 5, pp. 779-787, Sep. 2002.

[15] D. Casadei, G. Serra, A. Stefani, A. Tani, and L. Zarri, "DTC drives for wide speed range applications using a robust flux-weakening algorithm," IEEE Trans. Ind. Electron., vol. 54, no. 5, pp. 2451-2461, Oct. 2007.

[16] G. Abad, M. A. Rodriguez, and J. Poza, "Two-level VSC based predictive direct torque control of doubly fed induction machine with reduced torque and flux ripples at low constant switching frequency," IEEE Trans. Power Electron., no. 3, pp. 1050-1061, May 2008.

[17] P. Correa, M. Pacas, and J. Rodriguez, "Predictive torque control for inverter-fed induction machines," IEEE Trans. Ind. Electron., no. 2, pp. 1073-1079, Apr. 2007.

[18] R. Morales-Caporal and M. Pacas, "Encoderless predictive direct torque control for synchronous reluctance machines at very low and zero speed," IEEE Trans. Ind. Electron., vol. 55, no. 12, pp. 4408-4416, Dec. 2008.

[19] H. Miranda, P. Cortés, J. Yuz, and J. Rodríguez, "Predictive torque control of induction machines based on state space models," IEEE Trans. Ind. Electron., vol. 56, no. 6, pp. 1916-1924, Jun. 2009.

[20] T. Geyer, G. Papafotiou, and M. Morari, "Model predictive direct torque control - part I: Concept, algorithm and analysis," IEEE Trans. Ind. Electron., vol. 56, no. 6, pp. 1894-1905, Jun. 2009.

[21] G. Papafotiou, J. Kley, K. Papdopoulos, P. Bohren, and M. Morari, "Model predictive direct torque control - part II: Implementation and experimental evaluation," IEEE Trans. Ind. Electron., vol. 56, no. 6, pp. 1906-1915, Jun. 2009.

[22] J. Beerten, J. Verveckken, and J. Driesen, "Prediction-based ripple reduction in direct torque control of an induction machine," in Proc. IEEE ICEM '08, Villamoura, Portugal, Sep. 6-9 2008.

[23] — "Comparison of three-level torque hysteresis controllers for direct torque control," in Proc. IEEE EUROCON 2009, St.-Peterburg, Russia, May 18-23 2009. 
[24] G. Buja and R. Menis, "Steady-state performance degradation of a DTC IM drive under parameter and transduction errors," IEEE Trans. Ind. Electron., no. 4, pp. 1749-1760, Apr. 2008.

[25] P. Vas, Sensorless Vector and Direct Torque Control, ser. Monographs in Electrical and Electronic Engineering. New York: Oxford University Press, 1998.

[26] V. Ambrožič, M. Bertoluzzo, G. S. Buja, and R. Menis, "An assessment of the inverter switching characteristics in DTC induction motor drives," IEEE Trans. Power Electron., vol. 20, no. 2, pp. 457-465, Mar. 2005.

[27] http://www.triphase.com.

[28] J. Van den Keybus and J. Driesen, "Performance of real-time power electronic converter algorithms implemented on a personal computer," in Proc. IEEE ISIE 2006, Montreal, Canada, Jul. 9-13 2006, pp. 32813286.

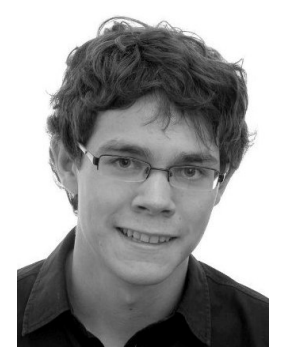

Jef Beerten (S'07) was born in Belgium in 1985. $\mathrm{He}$ received the M.Sc. degree in electrical engineering from the Katholieke Universiteit Leuven (K.U.Leuven), Leuven, Belgium, in 2008, where he is currently working towards the Ph.D. degree. He is a Research Assistant with the division ESATELECTA division of K.U.Leuven. His research interests include control strategies for power electronic systems.

Mr. Beerten received the Atlas Copco Thesis Award 2008 for his Master thesis on "Direct Torque Control of induction motors" and was the third winner of the IEEE Region 8 Student Paper Contest 2009. He holds a Ph.D. fellowship from the Research Foundation - Flanders (FWO)

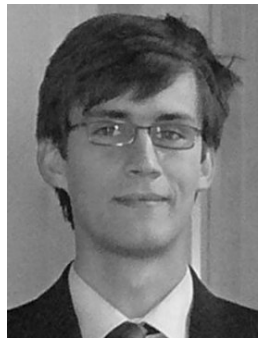

Jan Verveckken ( $\mathrm{S}^{\prime}$ 07) was born in Belgium in 1983. He received the M.Sc. degree in electrical engineering from the Katholieke Universiteit Leuven, (K.U.Leuven), Leuven, Belgium in 2006. He is currently a Research Assistant at K.U.Leuven, Leuven, Belgium and Instituto Superior Técnico, Lisboa, Portugal in a joint-diploma agreement. His research interests include sliding mode control, sensorless control, electrical machines and drives.

Mr. Verveckken is funded by the IWT (Institute for the promotion of science and technology in Flanders) and was the third winner of the IEEE Region 8 Student Paper Contest 2007.

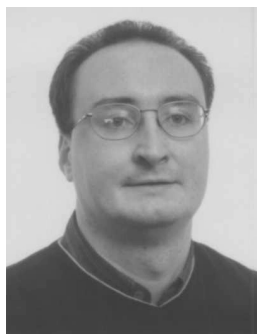

Johan Driesen (S'93 - M'97) was born in Belgium in 1973. He received the M.Sc. degree in electrotechnical engineering and the Ph.D. degree in electrical engineering from the Katholieke Universiteit Leuven (K.U. Leuven), Leuven, Belgium, in 1996 and in 2000 , respectively. His $\mathrm{Ph} . \mathrm{D}$. thesis was on the finite element solution of coupled thermal-electromagnetic problems and related applications in electrical machines and drives, microsystems, and power quality issues.

From 2000 to 2001, he was a Visiting Researcher with the Imperial College of Science, Technology, and Medicine, London, U.K. In 2002, he was with the University of California, Berkeley. He is currently an Associate Professor with the Department of Electrical Engineering (ESAT), K.U. Leuven, where he teaches power electronics and drives. Currently, he conducts research on distributed generation, including renewable energy systems and power electronics and its applications, for instance, in drives and power quality. 